\title{
Productivity as a Paradox of Acting as a Teacher in Self-regulatory Situations in Higher Education - Results of a Study Experiment in Teacher Training
}

\author{
Doreen Cerny \\ University of Teacher Education Salzburg, Austria
}

\begin{abstract}
This article questions and examines the possibilities and challenges of self-regulated learning in teacher-training programmes from the perspective of university teachers. In the following abstract, a study experiment at the Salzburg University of Education Stefan Zweig and the related empirical research are presented. In the course of this, results from the first group discussion in 2014 are discussed. In the analysis of the empirical material, it was possible to identify one phenomenon: university teachers picked out the aspect of productivity as a central theme. In this respect this aspect deserves far more attention, because in self-regulatory forms of teaching, the productive approach on both sides - university teachers as well as students - is countered in favour of a personal approach. The following, therefore, focuses on two aspects: (1) how do university teachers negotiate the subject of "productivity" in self-regulatory designed teacher training? (2) How do they see and perceive their "role" while acting as a teacher in higher education? The findings will be demonstrated on the basis of discussions about knowledge societies.
\end{abstract}

\section{Introduction}

"In recent years we have talked a lot about learning cultures, but little about teaching cultures" [1]. One has to agree with Reinmann's finding, although critical thinking on teaching methods, and thus automatically on learning methods, has its origins in antiquity. Only the nature of the discourse has changed. As a wide variety of professional disciplines (such as educational science) developed, research methodological approaches came along which allow the gathering of specific insights into the working and learning environments of the main protagonists with whom teaching and learning cultures identify professionally - university teachers and (prospective) teachers. From the teaching experience of teachers at the Salzburg University of Education Stefan Zweig, and based on feedback from student teachers, a sound basis for a pilot project with the objective "[...] that the students take more responsibility for their studies, their development and their professional approach, and as a result are able to assume individual responsibility" [2] has emerged. The $\mathrm{ABC}^{\text {plus }}$ study concept refers to a number of aspects, of which two should be mentioned at this point: (1) there is an awareness that teacher training has, in terms of discourse, arrived at the knowledge society and must position itself inside it. (2) That professional teacher training not only has to bring itself up to the "current status", but it has to progress to interactive negotiation processes "and thus be able to meet the challenges of today's teacher training. This transformation implements especially the maturity or respectively differentiation of an approach [italics in citation] in terms of a professional attitude, which is essential for both students and lecturers in the respective educational, didactic and school working alliances" [3]. The $\mathrm{ABC} 3^{\text {plus }}$ study experiment emerged from fundamental considerations as to how a proven and established teaching culture can differentiate itself, which aspects can be changed and which should be maintained.

It aims to adopt a "satellite function" on the following "expedition" by means of a section of teaching cultures. This can revolve in the inner orbit of the readers in order to enable identification and scrutinisation of the issue of productivity as a possible paradox in self-regulating teaching methods.

\section{Theoretical-conceptual starting points}

\subsection{Brief profile of the $\mathrm{ABC} 3^{\text {plus }}$ study experiment}

In the following, the aim is to present the study experiment to the reader in order to enable later classification of the findings of the empirical study. The concept and the theoretical basis of the $\mathrm{ABC} 3^{\text {plus }}$ study experiment came into being in a pilot article (see Cerny [4]). The theoretical and conceptual basis of the study experiment - and thus the underlying thoughts in this chapter - are published in Cerny [2], in which this present article has been extended to include the issue of productivity.

The study experiment focuses on the teachinglearning culture in teacher training at the Salzburg University of Education Stefan Zweig. It started in the 2013 winter semester and will be completed in the 2016 summer semester. Together with the pilot study connected to the study experiment "[it] operates on several levels which notionally and conceptually reflect the following approaches: general education (A), vocational education (B) and 
citizenship learning (C). The selected approach should be consolidated for teacher training at an action level as follows: it is fed by a system network which includes self-competence (e.g. the element of potential development), and specialist and technical expertise (e.g. the element of prevention of multidimensional alienation, deceleration theorem) and can be understood from the following theoretical background: (1) system constructivism (e.g. Luhmann/Parsons), (2) self-regulatory learning approach (e.g. Winne/Perry), (3) profession theorems (e.g. Schütze)" [2]. The training, education and citizenship approaches in the German translation provide the designation beginning with initial letters $\mathrm{ABC} 3^{\text {plus }}$, which give the name to the study experiment and which interact with each other on a theoretical level: "As a result [...] self-regulation, specialist and technical expertise, and resonance relationship are newly laid out and transcribed in the pilot study in terms of all those actor groups involved. Finally, the ${ }^{\text {plus }}$ in the name stands for all the necessary changes that are recognised in this (ongoing process) and which will be responded to immediately (as far as possible)" [3].

\subsection{Understanding self-regulation and paradoxes in teaching events}

The work with self-regulation and the paradoxes in teaching events revolves around the theoretical and practical debate in the study experiment. It was possible to present the empirical collection of experiences gathered by teachers in $\mathrm{ABC} 3^{\text {plus }}$ as a phenomenon: they were found or positioned under the premise of productivity.

In the following, the two aspects of selfregulation and paradoxes of conceptualtheoretical perspective are first outlined. The way productivity among university teachers is negotiated and the extent to which productivity can be a powerful player in teaching events is discussed in a further step in Chapter 3.

In both English- and German-speaking countries, there is extensive and saturated debate on the concept of self-regulation. It should be noted that this term is used in different ways and is often equated with the concept of selforganisation. At this point it is not the genesis of the two concepts and their competitive relationship towards each other that should be discussed, but it should be outlined how selfregulation is understood in $\mathrm{ABC} 3^{\text {plus }}$ (see also [2] Cerny): "The concepts of self-regulation (and self-control) refer to the controlling and regulatory aspects of independent learning [...]. Processes of regulation [...] happen when learners themselves influence their learning products or the learning methods used [...]. This regulation can be referred to as meta-cognitive, because observation analyses on-going cognitive processes in advance or in parallel. These include the essential processes which the person uses to accomplish the task. In other words, individuals act in a self-regulated manner if they themselves plan, select, monitor and modify strategies that they apply in the course of the acquisition of knowledge" [5]. The self-regulation approach (see Cerny [2] and [4]) is intrinsic to the study and is defined in the context of theories of motivation as situation-specific process-based components of learning and educational arrangements. It binds the subject-oriented components to these arrangements, as it were (see also [6]). Zimmermann [7] speaks of selfregulation as opposed to self-organisation, because both aspects of teaching-learning events are open to changing situations - intersubjectively and not exclusively due to external circumstances. Zimmermann [7] describes selfregulation as: "[...] as cyclical, because the feedback from prior performance is used to make adjustments during current efforts. Such adjustments are necessary because personal, behavioural, and environmental factors are constantly changing during the course of learning and performance $[\ldots] "$. The self-regulating (learning) phases are consequently applied cyclically, whereby in the first phase of "forethought", self-motivation beliefs, selfefficacy, outcome expectations, intrinsic interests. Zimmermann [7] demonstrate explicit connections to motivation theories that are closely intertwined from the perspective of the authors with constructivist perspectives.

Another central starting point is work with paradoxes in teaching events. Schütze [8] and [9] drew attention to issues which were contradictory in a professional setting for another group of actors (therapists), where his approach to dealing with paradoxes was also fruitful in the educational environment. Thus in the following, under the paradoxes of being a teacher, the aim is "[to understand; DC] constellations of action which are contradictory in themselves and which no longer work in their process of interaction" [10] (see also Cerny [2]). Teachers can moreover also [...] be confronted with (critical) transition phases both for students and for themselves, which may manifest as paradoxes of teaching events see [2] and [4]. Here the basic assumption that paradoxes are intrinsic to the (higher) educational field of activity follows insofar as it is the aim of the study experiment, in terms of theory-practice transfer, to create a space for students in which they can develop and strengthen their professional habitus. 
Against the background of awareness of the paradoxes of teaching events, the elements of the study experiment can be transferred from teacher training into "school" teaching practice [4]. As a result it is important to examine university teachers and to ask how they can develop their role as teachers in order to be able to prepare students for the challenges presented by schools in the 21 st century. In its empirical support, the study experiment also has to make the "possible variations of paradoxes" [2] visible, and to analyse these, particularly from the aspect of university teachers.

\section{Productivity as a paradox in teaching events from the perspectives of lectures - from a study experiment in teacher training}

\subsection{Methodological starting points for the study}

At this point, the methodical starting points from the concept paper of the study experiment will be outlined [4]: The superordinate subject of interest of the study experiment is to analyse how the learning and education processes aspired to within $\mathrm{ABC} 3^{\text {plus }}$ are perceived and reconstructed by the participating groups (students and university teachers). In order to be able to answer this question properly, a triangulative methodological approach (group discussions and questionnaires) was developed towards the respective connected issues. The results presented here are derived group discussions (about the method of group discussion see [11]) with teachers which were carried out in the 2013/2014 academic year and evaluated in line with the documentary method of interpretation [see 12]. At this point, sincere thanks are extended to Dr Henrike Winkler for her assistance in the collection and processing of data. During the group discussion a stimulus was provided to the interviewees by means of input, which might be questions or perhaps abstract or representational materials, aimed at enabling them first of all to recall a specific situation and then to talk about a topic (see also [11] and [13]). Unlike a guided process, the objective of this process is to refrain from influencing the discussion and to intervene in terms of the stimulus - a balancing act aimed at making it possible to lay open the experiential spaces of the participant. It should be noted at this point that this study - as is well known in discourses on qualitative research, and has by now been repeatedly and sufficiently discussed - does not aim to make representative statements in terms of divisions, and for this reason the quality criteria of quantitative research should not be applied. Rather, this process has the potential to generate new fields of research and to open up to continued work fields of investigation or activity which to date have been subject to little or no research. Using the group discussion method, modelled after Gurwitsch [14] it can on the one hand be identified how this joint participation was generally developed based on action-orientated knowledge, because teachers - as an association in the sense of a community communicate with each other and share their experiences. The group then represents their common experiences [11], which are regarded as collective memories and have formed through collective experience - the "conjunctive experiential space" [15] over the course of the semester. The task of the empirical study of this project is to conceptualise this knowledge which "is [exists as; DC] [....] atheoretic, not a conceptually theoretical collection" [13].

\subsection{The teacher as a "knowledge worker" and productivity as a paradox in teaching events}

In order to be able to approach the paradox of productivity in educational settings, at this point a digression from the educational science position was allowed: an autonomously acting individual needs knowledge and skills in order to be able to adequately respond to the everyday realities with which he or she is faced. There is a logic that "[k]nowledge and human ability complement each other since a lack of knowledge of the cause fails to take effect [...].That which is understood in observing the cause serves as a rule in the implementation." [16]. These thoughts of Francis Bacon are followed by other protagonists, such as Karl Liebknecht, who made it clear that knowledge is a powerful player in reshaping or preserving communities. Communities and society/societies have been reshaping themselves since the beginning of primitive and early societies. Nowadays, different scientific fields identify our existing society as a knowledge-based society. This concept arguably belongs to the "prominent time diagnostic services" [17] of current interdisciplinary discourses. In classical and postmodern debates about the concept of education as an emancipatory "must have" on the way to the self-responsible free subject, relevant others, appear in each case, who provide support or help to the individual in differentiating this on the way to an autonomous status. With regard to the subject of this article, these are in the young adulthood phase (trainee teachers) and at the level where they are shaping their professional biographies as university teachers. Of course it has to be borne in mind that in time the trainee teachers themselves will convey knowledge, and in addition to extracurricular socialisation factors they will be explicitly involved in the direct process of dissemination to 
another (younger) generation. All the more reason to critically question how it will be possible to pass on knowledge resources in such a way that the basic democratic order, which is shaped for example by freedom of opinion and religion, can be preserved. It should be asked whether Pisa studies or shortened evaluations in (higher) education contexts in terms of "output" or "skills" could be helpful here. The term "knowledge workers", which can be found in scientific discourse (see also [17], [18] or [19]), refers as follows to university teachers: In the discourses about social productivity, first environmental services are discussed: Lecturers are given the task of educating responsible, reflective teachers who can appropriately meet the tasks in the educational field in postmodern societies. This understanding of productivity includes "[...] the production of individual continuity as well as all activities [in a university/college-related setting; DC], which are at least potentially productive" [20], such as the reflected image on the teaching profession, autonomously questioning their own teaching, preparation and follow-up on teaching, and being up-to-date on educational issues. Lecturers are considered "knowledge workers" in the educational economics interpretation [19] because they have profession-specific knowledge, which students will later take advantage of. Lecturers pass on their knowledge - like a governance process.

To what extent do the sequences from the group discussions with the lecturers demonstrate a confrontation with productivity in teaching and consequent possible paradoxes?

- An essential component of the study is for the lecturers to exchange ideas, form teams, and take cross-course performance reviews. This integration was framed in two ways to be productive. First, the participants saw it as a relief if they were able to share with each other. Colleagues were also seen as "critical friends", which meant the exchange could be effective. Second, the lecturers described the meetings associated with this as a time penalty for their ordinary teaching preparation. Productivity was also discussed as a time factor and was a dominant marker in the sequences, i.e. the lecturers wanted more opportunities for professional exchange. The daily timetable at university can be seen at this point, according to Foucault [21], as a power component that the lecturers are subjected to. Productivity was also taken in the prevention of multiple content redundancies.

- They also describe how important the transfer and recoverability of self-regulatory training investment for future long-term human capital investment is to them. Students are expected to see themselves as animated by the content and presentation of university teaching and be able to enter the academic field of activity reflectively and with self-regulation. These teaching methods should also be reflected in the university curriculum, i.e. go beyond the study. At this point, it appears that both the students as well as colleagues and superiors are framed as coproducers who may ensure the self-regulatory approach as a fundamental principle is prospectively anchored.

- The lecturers point out that they want to reach students on equal footing, that the teachinglearning process can be seen as give and take. The dominant focus on the relationship level is certainly intrinsic to the educational interaction fields. In addition, Weber's belief can be applied here, because the professional setting of a university as a working system exists in the eyes of the lecturers through the negotiation process, which is marked by mutual trust [22, see also [19]. The lecturers are investing their resources into developing and maintaining the relationship of trust, so that the planned professional measures can have a long-term effect. In addition, some lecturers are regarded as models for the later teaching of students.

- In the group discussions, explicit and implicit meaning structures suggest that this type of teaching combines significant time and personal resources. In the existing system of higher education, however, some participants saw a limit to their autonomous development of professional teaching conduct, e.g. due to little time, different workloads, or financial savings. The paradoxes, however, did not remain exclusively natively virulent, but also referred to external actors such as partner schools, in which students take their practical courses.

\section{Conclusion}

Based on the empirical materials it was possible to work out that productivity in the teaching process is perceived both as a challenge and as potential. The university teachers surveyed have a differentiated approach regarding their own actions - namely the transfer of knowledge and the evocation of a professional being to their respective counterparts (trainee teachers). Their statements can be understood in the context of the knowledge-abilitybehaviour triad described by Reinmann [1]: knowledge in this context means that "as a university teacher, you need to be proficient in your subject, so you must have specialist knowledge at your command [...] That you should also be aware of human learning and have knowledge about lesson models, teaching methods and technical tools [...] But you also need knowledge that makes you critical in a university-didactic sense - i.e. knowledge about how different teaching and learning can be 
interpreted, which antinomies pervade the teachings [...]". According to Reinmann [1], ability requires more than didactic and professional knowledge; it also demands skills in planning and design as well as the logistics of university teaching. The results indicate, therefore, that the $\mathrm{ABC} 3^{\text {plus }}$ study experiment is also a learning arena for university teachers, because they had the opportunity, in "teaching events [at the university; DC] to continually test new things. Both - practising and testing - [could be; DC] carried out close to their own teaching." The empirical material further refers to one central aspect, in which the constellation of power in higher education teaching is noticeable and at the same time questioned: the university teachers involved declared themselves in favour of being "on a par" with the students in the course of teaching interaction as well as in discussions. The par principle endorses Reinmann's idea of practising and testing in teaching events at universities: "For this you need feedback 'on a par' and an open atmosphere, because: where experiments are carried out not everything can be successful, classical teaching evaluations are counterproductive and the search for beacons is discouraging [...] it [must] therefore be a priority to reflect [italics in citation] on one's own actions, to question routines and to analyse failures, but also to work out what one is particularly good at and why [...]" [1]. In the empirical material, the teachers also talk of attitudes and approaches instead of skills that they themselves were able to differentiate in the study experiment. According once again to Reinmann [1] "attitude" means everything "that an individual brings as willingness for an action [...] In addition, however, a never-ending discourse is needed over this very question - namely, what is the appropriate attitude for university teachers, to what guiding principles are they committed" [1]. Thus it is apparent in the empirical evidence that the teachers studied - as a guiding principle - despite the partly-perceived pressure to be efficient, did not identify themselves as those "knowledge workers" who merely impart "skills" and issue "do's and don'ts" to prospective teachers so that they are equipped for school lessons according to a formula. They reflect upon their attitude and as a result this manifests itself in a comprehensive understanding of dealing with paradoxes in teaching settings both at school and in university: precisely because people deal with each other professionally and always relate to each other, it is possible for paradoxes to emerge, whether in interaction, whether regarding the issues of temporal or spatial structure, due to organisational issues or to discrepancies in content. Ultimately, dealing with paradoxes in teaching events is then appropriate, if it can be responded to in a manner specific to the situation of the particular event and as a result of an autonomous, responsible approach. The productivity perceived in self-regulatory teaching methods can thus be read as self-insurance for one's own professional activities. On the other hand the perceived demands of productivity in the higher education setting provide a structure of opportunity to scrutinise and to differentiate one's own professional actions.

\section{References}

[1] Reinmann, G., (2015) Lehrkompetenzen von Hochschullehrern in R. Egger/C. Wustmann (Edt.) Forschungsgeleitete Lehre in einem Massenstudium. Wiesbaden: Springer, pp. 55-75.

[2] Cerny, D., (2015) Der Studienversuch $A B C 3^{\text {plus }}$ und die Rekonstruktion professioneller Handlungswelten als Beitrag zum Diskurs über LehrerInnenbildung in PHScript. Beiträge aus Wissenschaft und Lehre, Schwerpunkt Neue Lehr- und Lernformen, 09/2015, pp. 18-25.

[3] Cerny, D./Niederreiter, H., (2015): Prolog: Zur Ideengeschichte des Studienversuchs $\mathrm{ABC}^{\text {plus }}$ in $\mathrm{PH}-$ Script. Beiträge aus Wissenschaft und Lehre, Schwerpunkt Neue Lehr- und Lernformen, 09/2015, pp. 16-17. $\begin{array}{cccc}\text { [4] Cerny, D., } & \text { (2014) } & \text { Theoretisches } & \text { und } \\ \text { forschungsmethodisches } & \text { Konzeptpapier } & \text { zum }\end{array}$ Studienversuch $\mathrm{ABC}^{\text {plus }}$ (unveröffentlichtes Papier unter Mitarbeit von: Kaiser-Gruber, Theresia, Niederreiter, Heike \& Schober, Christine).

[5] Konrad, K., (2014) Lernen lernen - allein und mit anderen. Wiesbaden: Springer.

[6] Winne, P.H., Perry, N.E., (2000) Measuring selfregulated learning in M. Boeckaerts/P.R. Pintrich et. al. (Edt.) Handbook of Self-Regulation. San Diego: Academic Press, pp. 531-566.

[7] Zimmermann, B. J., (2000) Attaining Self-Regulation. A social cognitive Perspective in M.Boeckaerts/ P.R. Pintrich, et. al. (Edt.) Handbook of Self-Regulation. San Diego: Academic Press, pp. 13-39.

[8] Schütze, F., (1992) Sozialarbeit als „bescheidene Profession" in B. Dewe/ W. Ferchhoff, W. et. al. (Edt.) Erziehung als Profession. Zur Logik professionellen Handelns in pädagogischen Feldern. Opladen: Leske+Budrich, pp.132-170.

[9] Schütze, F., (1996). Organisationszwänge und hoheitsstaatliche Rahmenbedingungen im Sozialwese in A. Combe/W. Helsper, (Edt.) Pädagogische Professionalität. Untersuchungen zum Typus pädagogischen Handelns. Frankfurt am Main: Suhrkamp, pp. 183-275.

[10] Prokopp,K., (2000) Grenzschwierigkeiten,Antinomien und Paradoxien des Lehrer(innen)handelns - Ergebnisse der Fallanalyse des Entwicklungsprozesses einer Einzelschule [42 Absätze] in FQS, Volume 1, No.1, Art.29. [WWW Dokument] Verfügbar unter: http:/nbnresolving.de/urn:nbn:de0114-fqs0001297. [Datum des Zugriffs: 01.12.2012]. 
[11] Bohnsack, R., (2000) Gruppendiskussion in U. Flick/E.von Kardoff, E. et. al. (Edt.) Qualitative Forschung. Ein Handbuch. 5. Auflage. Opladen: UTB, pp. 369-384.

[12] Bohnsack, R., Nentwig-Gesemann, I./Nohl, A., (2007) Die dokumentarische Methode und ihre Forschungspraxis. Grundlagen qualitativer Sozialforschung. 2. erw. Auflage. Wiesbaden: Springer.

[13] Przyborski, A., Riegler, J., (2010).Gruppendiskussion und Fokusgruppe in G. Mey/K. Mruck (Edt.) Handbuch Qualitative Forschung in der Psychologie. Wiesbaden: Springer [DOI: 978-3-531-92052-8_31].

[14] Gurwitsch, A., (1976) Die mitmenschlichen Begegnungen in der Milieuwelt. Berlin: de Gruyter.

[15] Bohnsack, R., (1989). Generation, Milieu und Geschlecht - Ergebnisse aus Gruppendiskussionen mit Jugendlichen. Opladen: Leske+Budrich.

[16] Bacon, F., ([1620] 1990) Neues Organon, Teilband 1 Lateinisch-deutsch, edt. by W. Krohn, Hamburg: Felix Meiner.

[17] BöschenS./Schulz-Schaeffer, I., (2003). Einleitung in S. Böschen/I. Schulz-Schaeffer (Edt.) Wissen in der Wissensgesellschaft. Wiesbaden, Springer, pp. 9-25.

[18] Heidenreich, M., (2003) Die Debatte um die Wissensgesellschaft in S. Böschen/I. Schulz-Schaeffer (Edt.) Wissen in der Wissensgesellschaft. Wiesbaden, Springer, pp. 25-55.

[19] Stehr, N., (2003) Das Produktivitätsparadox in S. Böschen/I. Schulz-Schaeffer (Edt.) Wissen in der Wissensgesellschaft. Wiesbaden, Springer, pp. 77-97.

[20] Aner, K./ Hammerschmidt, P., (2008) Zivilgesellschaftlich produktiv altern. Eine kritische Analyse ausgewählter Modellprogramme in $\mathrm{M}$. Erlinghagen/K. Hank (Edt.) Produktives Altern und informaelle Arbeit in moderenen Gesellschaften. Wiesbaden: Springer, pp. 259-276.

[21] Foucault, M., (1977) Überwachen und Strafen. Die Geburt des Gefängnisses. Frankfurt am Main: Suhrkamp.

[22] Weber, M., ([1913]/1981) Some Categories of Interpretive Sociology in The Social Quarterly, 22 (Spring 1981), pp. 151-180. 